\title{
RESEARCH AND DEVELOPMENT A REMOTELY OPERATED UNDERWATER VEHICLE
}

\section{TUAN PHAN ANH, QUANG LE, HUONG PHAM THI THANH \& CONG DO THANH}

Hanoi University of Science and Technology, Hanoi, Vietnam

\begin{abstract}
This paper presents a research and development of a Removed Operated Underwater Vehicles (ROV). It is torpedo-shaped ROV with $3.2 \mathrm{~m}$ in length, $0.3 \mathrm{~m}$ in diameter. The main hull of the ROV is made by steel and aluminum. In this design, the ROV is driven by flexible steering system. In horizontal direction, the ROV is driven by a couple of blade ruder. In vertical direction, the ROV is driven by a couple of thrusters. For increasing the ROV stability, three fixed fins are designed with hydro dynamic profiles and located on the back and at the rear of the ROV. Resistance of the ROV has been estimated by CFD method before selecting its main propulsive propeller and selection of the main electrical motor. For communication and controlling, the ROV uses both wire and wireless technologies. The ROV pulls a float when it moving underwater. Communication between the ROV and the float is wire communication. Communication from the float to a control station on land is wireless.

KEYWORDS: ROV, Torpedo-Shaped, Flexible Devices, Resistance, CFD
\end{abstract}

Received: Oct 08, 2020; Accepted: Oct 28, 2020; Published: Nov 05, 2020; Paper Id.: IJMPERDOCT202024

\section{INTRODUCTION}

Unmanned Underwater Vehicles (UVV) are including Removed Operated Underwater Vehicles (ROV) and Autonomous Underwater Vehicles (AUV). While ROVs have to use cables for controlling and driving, AUVs are controlled and driven by coded programs.

Removed Operated Underwater Vehicle has risen consistently since they were introduced in the 1960s, and find their most frequent use in scientific research and data collection. In 1978, AMETEK (USA) successfully built an ROV called SCORPIO with can diving depth of up to 1000 meters [1]. This medium size class of ROV refers to electro-hydraulic vehicles ranging from 20-100 horsepower typically, which can only carry moderate payloads and have limited throughframe lift capability. These ROVs range in weight from 1,000 to 2,200 kg with typical payload capacity range from 100 to $200 \mathrm{~kg}$. Since the 1980s, the offshore oil industry has used ROVs to assist in offshore development, especially as waters became too deep for human divers to go.ROVs have also become famous for recovering shipwrecks, including the famous Titanic shipwreck. The first commercial ROVs on the world could be considered as the Hydro Products RCV 225 and RCV 150 [2].

Todays, ROVs are popular used in oceanic research, for purposes such as current and temperature measurement, ocean floor mapping, and hydrothermal vent detection. Removed Operated Underwater Vehicles utilize seafloor mapping, bathymetry, digital cameras, magnetic sensors, and ultrasonic imaging. 


\section{THE DESIGN OF REMOTELY OPERATED UNDERWATER VEHICLE}

\subsection{Hull form of the ROV}

The hull form of the Removed Operated Underwater Vehicle in this design is a torpedo-shaped ROV. It is including three main parts and make from steel and aluminum. The fore and the rear of the AUV hullare parabolic shapes, the middle of the AUV hull is a pipe. Total length of the ROV hull is $3.2 \mathrm{~m}$, the diameter of the ROV is $0.3 \mathrm{~m}$. The ROV has a camera with LED light system in its fore for recording video under water. Figure 1 shows the hull form of the ROV.

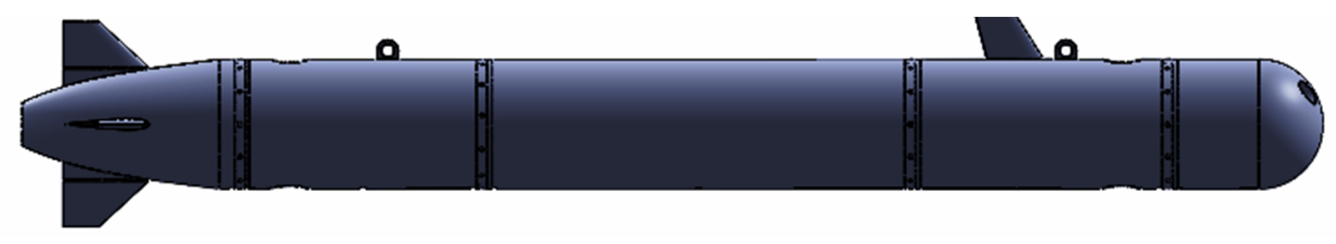

Figure 1: Hull form of the ROV

This ROV using both wire and wireless technology for communication and controlling. The ROV and a float thatpulled by the ROV are communicated together via a cable. The float and a mother ship or control station on the land communication via wireless technology.

\subsection{Flexible Steering System}

The Removed Operated Underwater Vehicle uses a combination of blade rudders, fixed fins and thrusters for steering and stabilizing. For horizontal steering, the ROV is driven by a couple of blade rudders that are aerodynamic profiles andplacedat above and belowat the rear of the ROV. Those two blade ruder are mounted on the same steering shaft. The shaft rotates those blades rudders is in vertical direction and goes through the ROV hull at its symmetrical axis. The steering shaft of the blade rudders connect to the ROV hull by ball bearings. The blades rudders are rotated and controlled via their shaft by a servo motor. The flexible steering system of the ROV is shown in Figure 2.
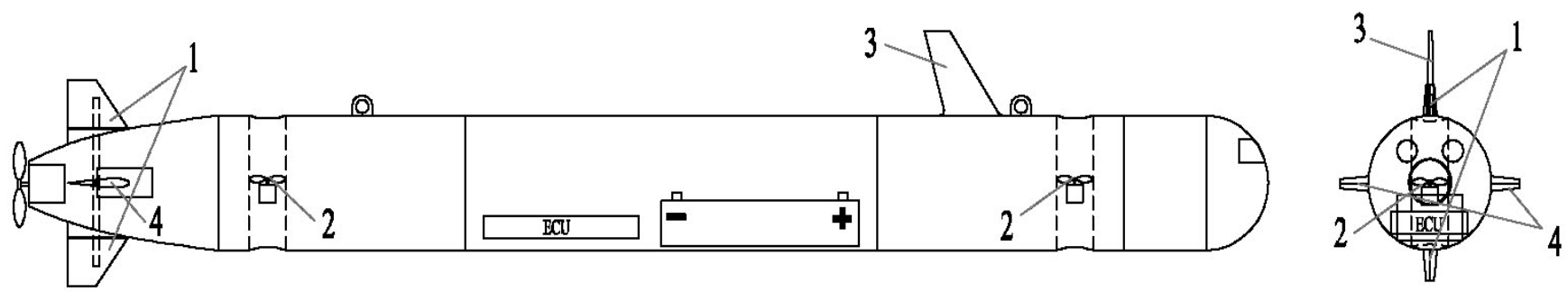

\section{1: Horizontal blade rudders2: Vertical steering thrusters3: Big fixed fin4: Small fixed fins}

Figure 2: Flexible steering system of the ROV

For vertical steering, the ROV use two thrusters. To enhance the ability to generate thrust and torque for steering the ROV, the thrusters are set inside ducts. The thrusters are driven by specialized brushless motors that could be operated normally underwater environment.

In addition, for increasing the stability for the ROV, a set of three fixed fins is designed. They are including a bigger fin with hydrodynamic profile of NACA 0025 is placed on the back of the ROV, two smaller fins placed on left and right at the rear of the ROV. 


\subsection{Main Propulsive Propeller}

For moving forward and backward, the Removed Operated Underwater Vehicle uses a main propulsive propeller. It is a propeller with $160 \mathrm{~mm}$ in diameter and four blades. For driving the main propulsive propeller, a specialized brushless motor that could be operated normally underwater environment. The power of the brushless motor is around $1.2 \mathrm{~kW}$ at the rotating speed of $4500 \mathrm{RPM}$. The form of the main propulsive propeller is shown in Figure 3.

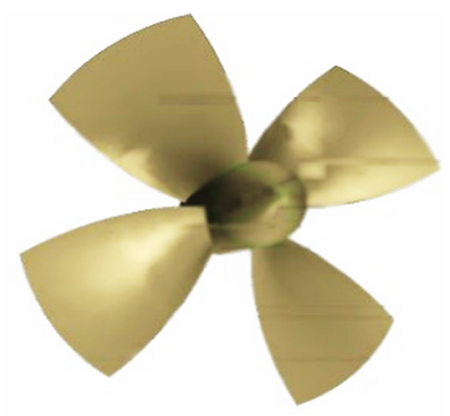

Figure 3: Main Propulsive Propeller of the ROV

\subsection{Communication}

For communication and controlling, the Removed Operated Underwater Vehicle uses both wire and wireless technologies. The ROV pulls a float when it moving underwater. Communication between the ROV and the float is wire communication and from the float to a mother ship or an earth station on land is wireless communication. The two communications are shown by block in Figure 4 .

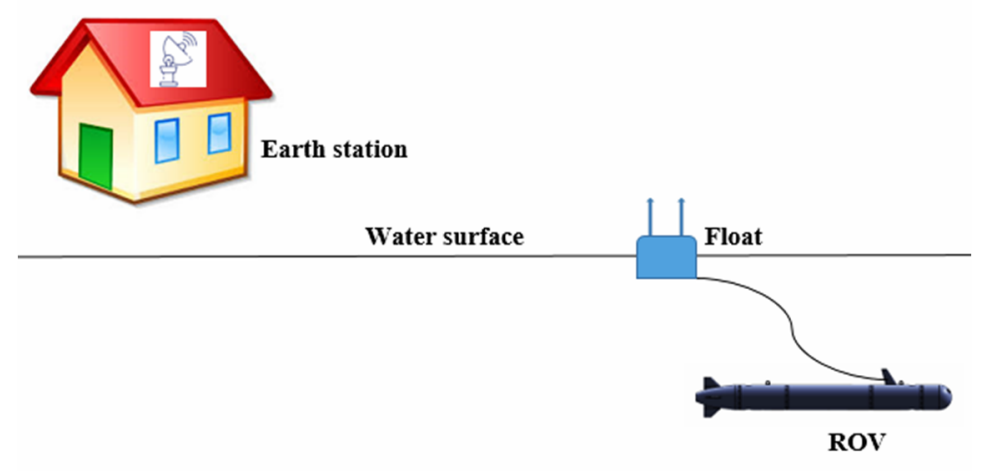

Figure 4: Communication and Controlling of the ROV

The ROV has an underwater camera with LED light support for recording. The ROV will be controlled form earth station on land by a driver who observation underwater around the ROV via its camera.

\section{CFD CONDUCTION}

\subsection{Domain and Boundary Conditions}

Computational domain for the CFD simulation in this study is showing in Figure 5. It is a cylinder tunnel with $650 \mathrm{~m}$ in length (around 215 times of the ROV length) and $150 \mathrm{~m}$ of diameter (around 500 times of ROV diameter). The submarine is located on central line of the cylinder and at $250 \mathrm{~m}$ far from the inlet of the flows.

In this study, Boundary Conditions of the CFD simulation are: the temperature is set at $27^{\circ} \mathrm{C}$, equivalent to $300^{\circ} \mathrm{K}$, the 
pressure at the outlet of the cylinder tunnel is set equal to the atmospheric pressure, the ROV and the cylinder tunnel are stationary and considered as walls, density of the air is set at $\rho=1,225 \mathrm{~kg} / \mathrm{m} 3$, air viscosity coefficient is set at $1.7894 \times 10^{-5} \mathrm{~kg} /(\mathrm{ms})$, density of water is $998.2 \mathrm{~kg} / \mathrm{m} 3$, the viscosity of water is $1.003 \times 10^{-5} \mathrm{~kg} /(\mathrm{ms})$.

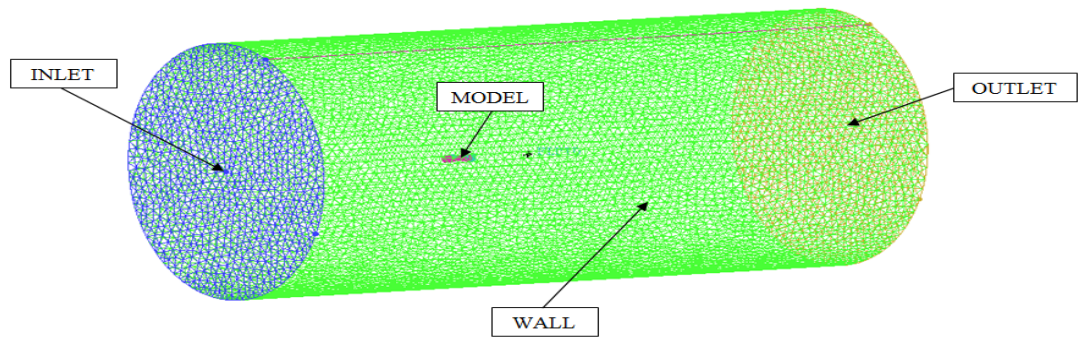

Figure 5: Domain for the CFD conduction of the ROV

\subsection{Turbulent Model}

In this study, $\mathrm{k}-\varepsilon$ turbulence model is used. The $\mathrm{k}-\varepsilon$ turbulence model is the most common model used in computational fluid dynamics to simulate turbulent flows. It is a model with two equations which represent turbulence by means of two transport equations. The k- $\varepsilon$ model was first used to improve the mixing-length model, as well as to find an alternative to algebraically prescribing turbulent length scales in moderate to high complexity flows. The first transported variable determines the energy in the turbulence is called turbulent kinetic energy, $\mathrm{k}$. The second transported variable is the turbulent dissipation, $\varepsilon$, which determines the rate of dissipation of the turbulent kinetic energy [3], [4].

$$
\begin{aligned}
& u \frac{\partial u}{\partial x}+v \frac{\partial u}{\partial y}+w \frac{\partial u}{\partial z}=-\frac{1}{\rho} \frac{\partial p}{\partial x}+\frac{1}{\rho}\left(\frac{\partial \tau_{x y}}{\partial y}+\frac{\partial \tau_{x z}}{\partial z}\right)+F_{x} \\
& u \frac{\partial v}{\partial x}+v \frac{\partial v}{\partial y}+w \frac{\partial v}{\partial z}=-\frac{1}{\rho} \frac{\partial p}{\partial y}+\frac{1}{\rho}\left(\frac{\partial \tau_{y x}}{\partial x}+\frac{\partial \tau_{y z}}{\partial z}\right)+F_{y} \\
& u \frac{\partial w}{\partial x}+v \frac{\partial w}{\partial y}+w \frac{\partial w}{\partial z}=-\frac{1}{\rho} \frac{\partial p}{\partial z}+\frac{1}{\rho}\left(\frac{\partial \tau_{z x}}{\partial x}+\frac{\partial \tau_{z y}}{\partial y}\right)+F_{z}
\end{aligned}
$$

where,

$\mathrm{u}, \mathrm{v}, \mathrm{w}$ are components of velocity vector,

$\rho$ is density of environment,

$\mathrm{p}$ is static pressure,

$\tau$ is shear stress tensor,

Fx, Fy, Fz are components of gravitational body force.

\section{RESULTS AND DISCUSSIONS}


In this study, CFD simulations were calculated for the state of the Removed Operated Underwater Vehicle operating at a depth of 20 meters, forward and backward cases. The velocities of the ROV is assumed to be $0.5 ; 1.0 ; 1.5 ; 2.0 ; 2.5$ and $3.0 \mathrm{~m} / \mathrm{s}$.

\subsection{Pressure Distribution}

After conducting CFD simulation, the pressure distribution around the hull surface of the Removed Operated Underwater Vehicle is shown as in the following figures.
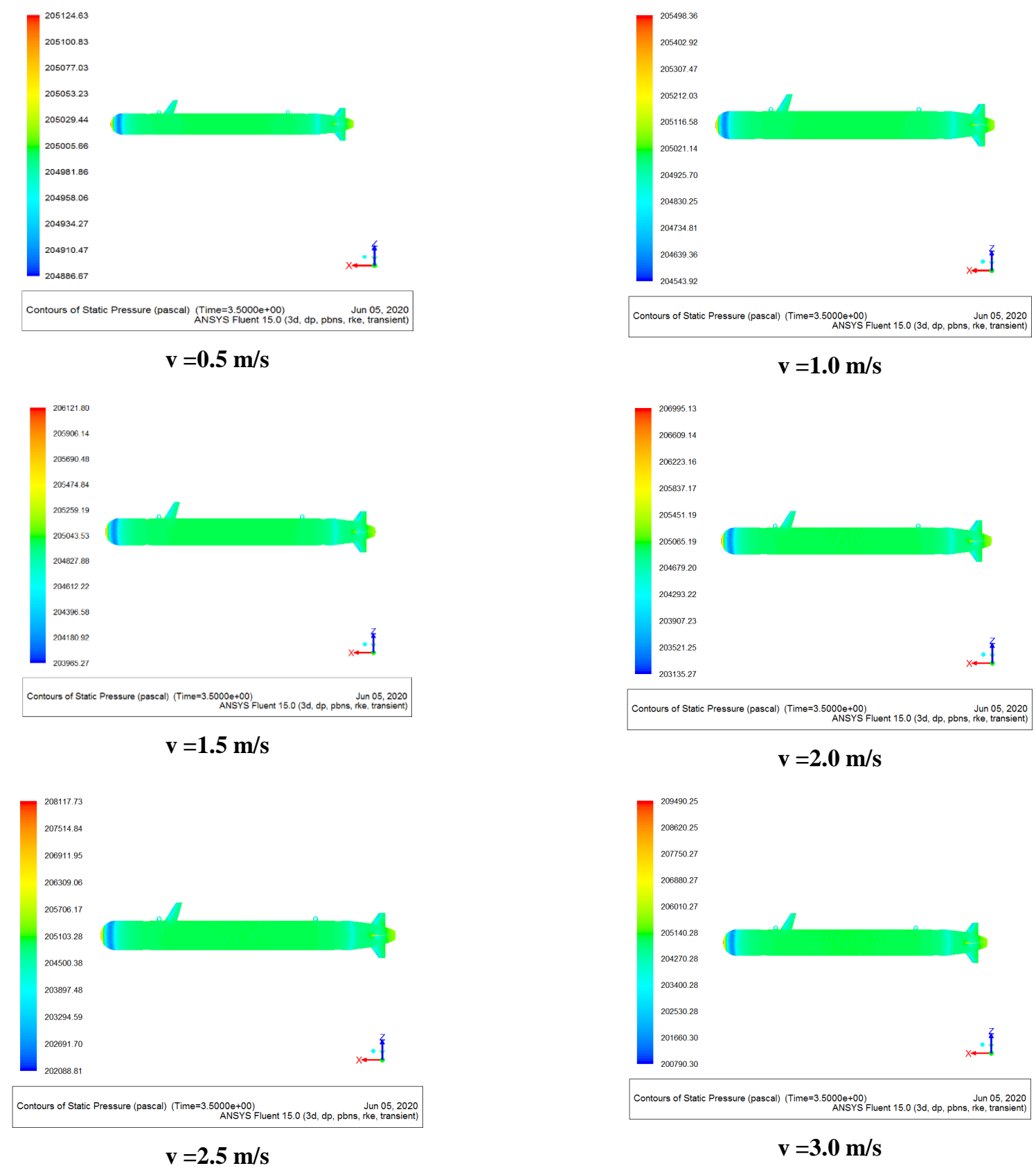

Figure 6: Pressure distribution around the hull surface of the ROV 


\subsection{Flow Distribution}

The flow distribution around the hull of the Removed Operated Underwater Vehicle are shown as in the Figure 7 and Figure 8.
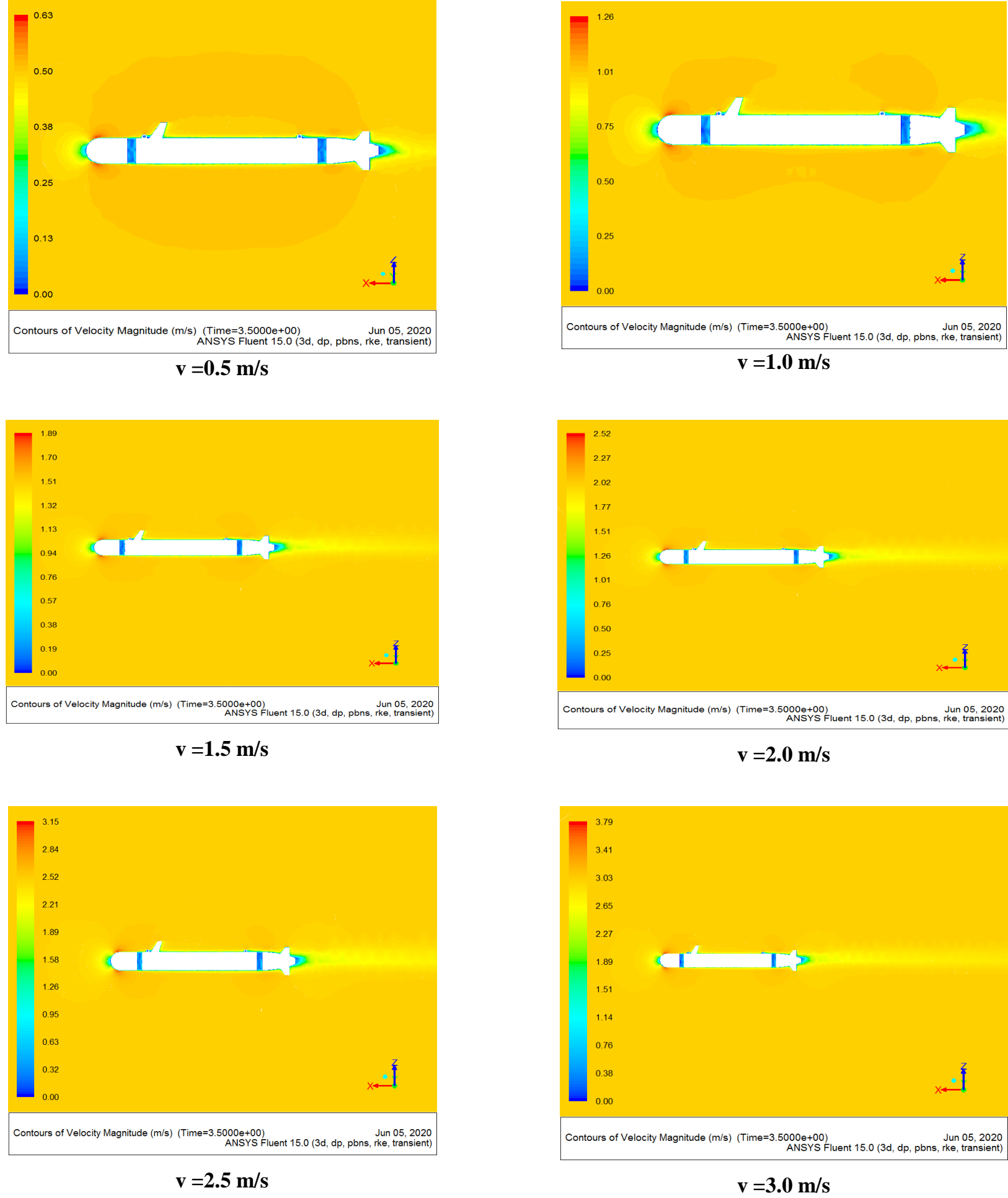

Figure 7: Flow distribution around the hull of the ROV in vertical plane 

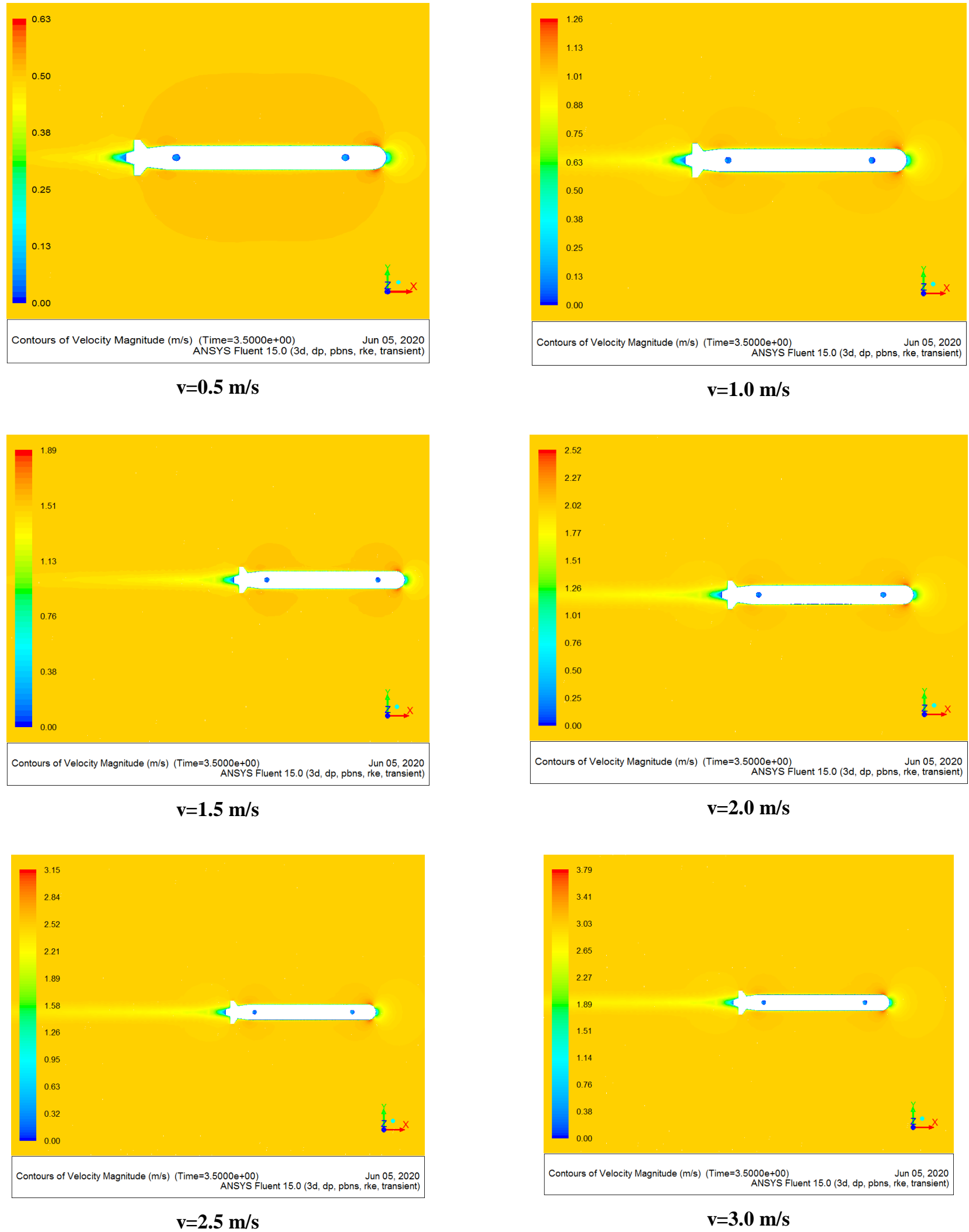

Figure 8: Flow distribution around the hull of the ROV in horizontal plane 


\subsection{ROV Resistant when Run Forward}

Component resistances of the Removed Operated Underwater Vehicle at different running velocities in forward movement are summarized as the Table 1 .

Table 1: Resistances of the ROV when running forward

\begin{tabular}{|l|l|l|l|l|l|l|}
\hline Velocity $(\mathrm{m} / \mathrm{s})$ & 0.5 & 1.0 & 1.5 & 2.0 & 2.5 & 3.0 \\
\hline Pressure resistance & 0.68 & 2.61 & 5.91 & 10.48 & 16.56 & 24.03 \\
\hline Viscous resistance & 1.27 & 4.11 & 8.45 & 14.17 & 21.20 & 29.47 \\
\hline Total resistance & 1.95 & 6.72 & 14.35 & 24.66 & 37.76 & 53.50 \\
\hline
\end{tabular}

Figure 9 shows the graphs of resistant curves when the ROV moving forward. The graphs show that when the ROV moving forward at low speeds, the pressure resistance is small compare with the viscous resistance. However, when the ROV moves at a higher velocity, the effect of the pressure resistance over the total resistance is increasing significantly. At high moving velocities, the proportion of component resistances in the total resistance is more balanced than at the low moving velocities of the ROV.

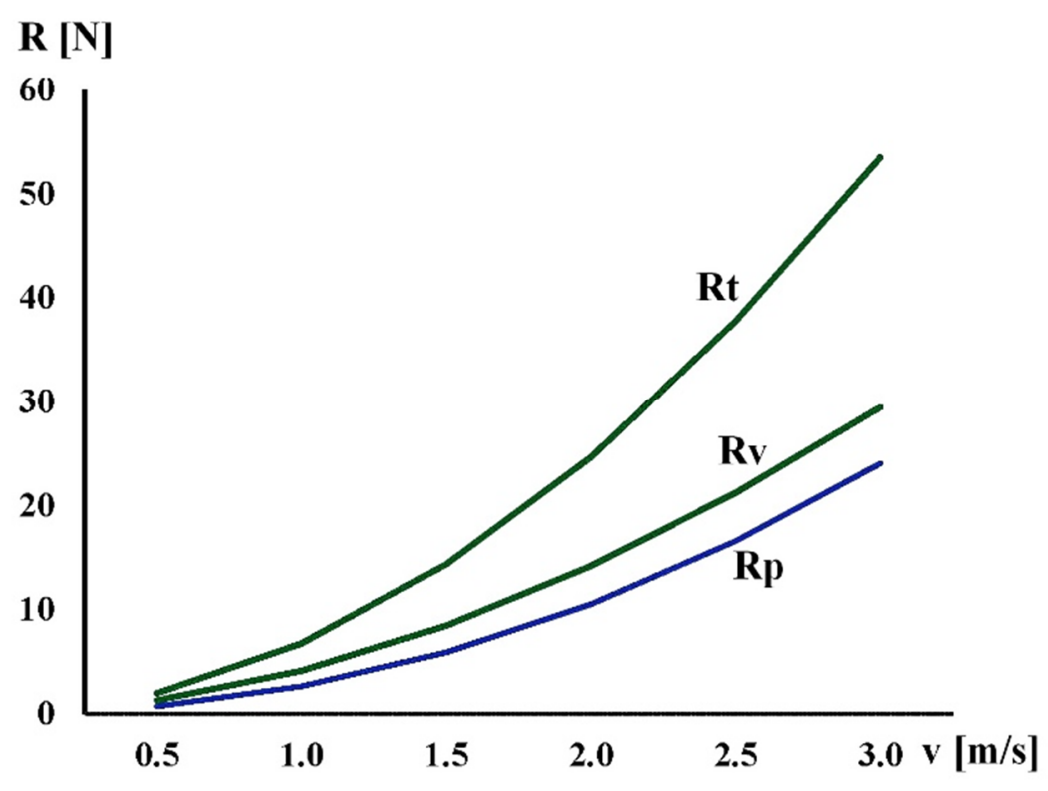

Figure 9: ROV Resistance in Moving Forward

\subsection{ROV Resistance when Run Backward}

Component resistances of the Removed Operated Underwater Vehicle at different running velocities in backward movement are summarized as the Table 2.Figure 10 shows the graphs of resistant curves when the ROV moving backward.

Table 2: Resistances of the ROV when Running backward

\begin{tabular}{|l|l|l|l|l|l|l|}
\hline Velocity $(\mathrm{m} / \mathrm{s})$ & 0.5 & 1.0 & 1.5 & 2.0 & 2.5 & 3.0 \\
\hline Pressure resistance & 0.83 & 3.25 & 7.42 & 13.31 & 20.72 & 30.23 \\
\hline Viscous resistance & 1.23 & 4.07 & 8.45 & 14.19 & 21.22 & 29.50 \\
\hline Total resistance & 2.07 & 7.33 & 15.87 & 27.50 & 41.95 & 59.72 \\
\hline
\end{tabular}




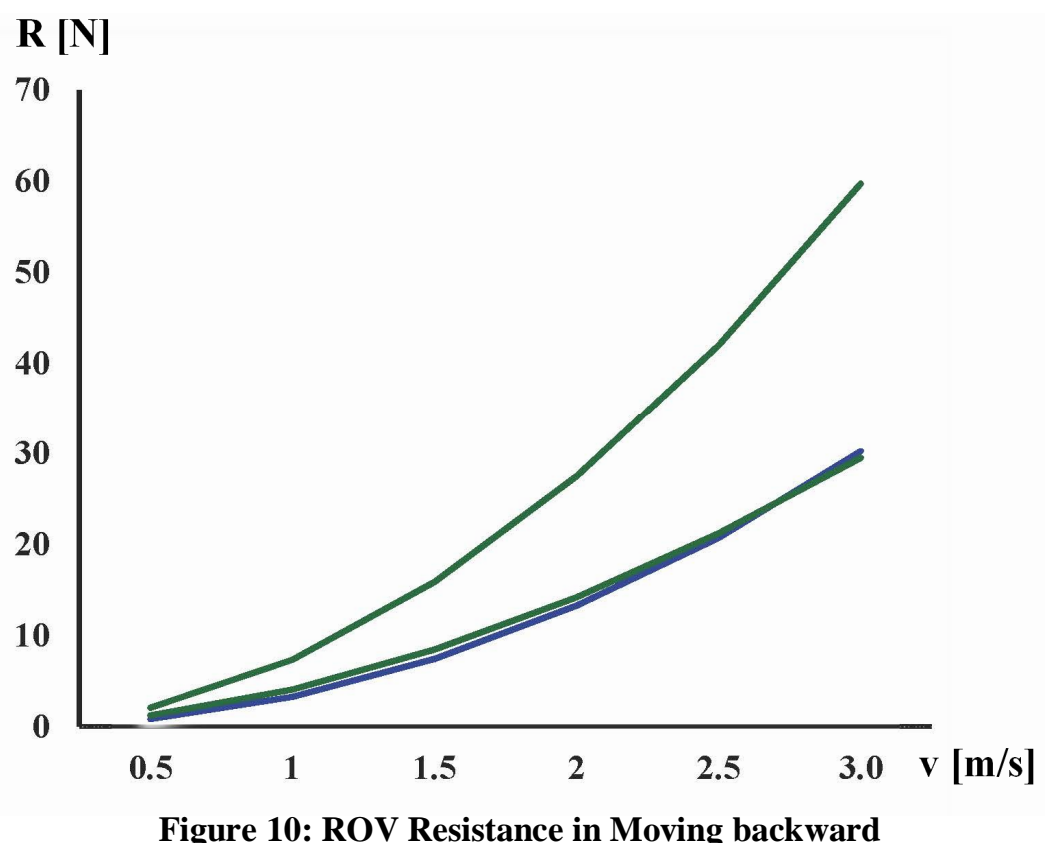

Figure 10 shows that when the ROV moving backward, the component resistances are not so difference. The proportion of component resistances in the total resistance is balanced in all velocities of the ROV.

\section{CONCLUSIONS}

The authors have presented a R\&D study on a Removed Operated Underwater Vehicle in this paper. It is a torpedo-shaped ROV.

The research team has studied on the hydrodynamics of the ROV by CFD numerical simulation method. CFD is used for estimated resistance of the ROV. The simulation results of the resistance estimation show that in the low speed range, the total resistance of the ROV is mainly created by the viscous resistance. However, when moving to a higher velocity, the viscous resistance and the pressure resistance have a similar influence on the total resistance of the ROV.

Research found that in cases of the ROV running forward and backward, the viscous resistance does not change significantly. The total resistances change between these two cases is mainly the change by the pressure resistances. When the ROV is running in backward mode its total resistance is higher compared to run in forward mode.

\section{ACKNOWLEDGEMENT}

This work is supported by the Ministry of Science and Technology with project code: NĐT.68.RU/19.

\section{REFERENCES}

1. http://cyberneticzoo.com/underwater-robotics/1978-scorpio-rov-american, accessed in Oct. 2020.

2. Robert L. Wernli, Robert D. Christ, Observation Class ROVs Come of Age, Sixth International Symposium on Underwater TechnologyUT2009, Wuxi, China, April 2009.

3. Tuan Phan Anh, Quang Vu Thanh, He Ngo Van, Quang Le, Huong Pham Thi Thanh, Estimation resistance of an explorer submarine, Journal of Mechanical Engineering Research \& Developments, Vol. 43, No. 1(2020), pp. 264-271, ISSN: 10241752. 
4. Phan Anh Tuan, Nguyen Dai Quy, Influence of blade tip clearance on performance of multistage compressors, Journal of Mechanical Engineering Research \& Developments, Vol. 43, No. 4(2020), pp. 115-122, ISSN: 1024-1752. 